\title{
Hereditary Retinoblastoma
}

National Cancer Institute

\section{Source}

National Cancer Institute. Hereditary Retinoblastoma. NCI Thesaurus. Code C8495.

An inherited malignant tumor that orig inates in the nuclear layer of the retina. A predisposition to retinoblastoma has been associated with $13 q 14$ cytogenetic abnormalities. Patients with the inherited form appear to be at increased risk for secondary nonocular malignancies such as osteosarcoma, malignant fibrous histiocytoma, and fibrosarcoma. 